\title{
Addressing cardiometabolic risk in adults with spinal cord injury: acting now despite knowledge gaps
}

\author{
S. Sabharwal (iD ${ }^{1,2}$
}

Received: 10 October 2019 / Accepted: 25 October 2019

(c) Crown 2019

\begin{abstract}
This perspective advocates for the adoption of recently published clinical practice guidelines on identifying and managing cardiometabolic risk after spinal cord injury (SCI). It makes the case for acting now, with the knowledge that we currently have, while continuing to address knowledge gaps with high-quality research studies in this area. Cardiovascular disease is a leading cause of death in people with SCI. Cardiometabolic disease (CMD) and risks are more likely to be overlooked after SCI. Unique SCI-related considerations impact both assessment and management of cardiometabolic risk. Risk factors and components of CMD including obesity, impaired glucose tolerance/insulin resistance, dyslipidemia, and hypertension should be evaluated and managed to optimize the cardiometabolic health of this population. While it would be optimal to base all care on high-quality evidence-based research, its absence should not be an excuse for inaction. Applying what is currently known and filling the research gaps with empirical recommendations based on clinical rationale and expert consensus is both appropriate and necessary till more definitive SCI-specific evidence becomes available.
\end{abstract}

\section{Introduction}

Clinical practice guidelines on "Identification and Management of Cardiometabolic Risk after Spinal Cord Injury" have recently been published [1]. This article responds to some related why, what, and how questions and makes the case for using these guidelines to address cardiometabolic risk in current spinal cord injury (SCI) practice.

\section{Why do we need these guidelines?}

Cardiovascular disease is a leading cause of death in people with SCI. Current research collectively indicates an increased prevalence of several cardiometabolic risk factors in individuals with SCI (Table 1) [2-9]. The reported prevalence of cardiometabolic disease (CMD) components in the SCI population does vary considerably [2, 3, 10-16], and legitimate concerns can be raised about relatively small numbers of subjects, inadequate controls for confounding

\footnotetext{
S. Sabharwal

Sunil.sabharwal@va.gov

VA Boston Health Care System, Boston, MA, USA

2 Harvard Medical School, Boston, MA, USA
}

variables, diverse study populations and differences in measured outcomes that contribute to these discrepancies [12]. Regardless, attention to cardio-metabolic risk is increasingly important in the care of these individuals since cardiovascular disease is recognized as a major cause of mortality and morbidity in people with SCI especially with aging and the increase in life-span of this population [2, 6, 9, 14, 17-21].

Cardiometabolic disease and risks are more likely to be overlooked after SCI. CMD is often asymptomatic and insidious in onset. Health care providers may overlook such less conspicuous aspects of health in the context of multiple SCI-related issues that require attention. Moreover, atypical presentations of cardiac events can contribute to delayed or missed diagnosis of cardiac disease in those with SCI above the T5 level who often do not get chest pain with coronary events or angina because the cardiac sympathetic afferent input is interrupted [22-24]. Shortness of breath from cardiac causes may be erroneously attributed to respiratory or deconditioning effects of SCI. In contrast to the relatively low prevalence of typical clinical symptoms of myocardial ischemia, reports suggest a much higher prevalence of ischemia detected on thallium stress tests or myocardial perfusion scans in people with SCI [25, 26]. Generalists often lack SCI-specific knowledge, so people with SCI not uncommonly look to their SCI specialists as also their de 
Table 1 Potentially increased cardiovascular risk factors after SCI

Decreased physical activity

Low HDL cholesterol

Impaired glucose tolerance, insulin resistance

Increased proportion of body fat due to loss of FFM

Potential effects of SCI on emerging risk factors

$H D L$ high-density lipoprotein, $F F M$ fat-free mass

facto primary care physicians. However, SCI providers without an internal medicine or primary care background may not keep up with cardiometabolic literature, so SCIspecific guidelines could be helpful in drawing needed awareness and attention to this issue.

Unique SCI-related considerations impact assessment and management of cardiometabolic risk. Effects of SCI on body composition and physiology have an impact on both assessment and management of cardiometabolic risk, so some aspects of guidelines developed for the general population may not apply to individuals with SCI. For example, traditional cut-offs for defining overweight and obesity by body mass index (BMI) may underestimate adiposity due to loss of fat-free mass (FFM) from sarcopenia and osteopenia following SCI, and the presence of abdominal muscle paralysis makes waist circumference a less valid measure of abdominal adiposity [12, 27]. Orthostatic hypotension and autonomic dysreflexia after SCI can impact the interpretation of blood pressure (BP) measurement for diagnosing hypertension [1, 4]. SCI affects options for exercise prescription [28-31]. Reduced caloric expenditure and basal energy requirements impact recommended caloric intake [32]. Unique SCI-related factors can impact pharmacotherapy options for hypertension and for other risk factors and CMD components [4].

\section{What are the recommended guidelines to address CMD in adults with $\mathrm{SCl}$ ?}

Recommendations from the published guidelines on identifying and managing cardiometabolic risk after SCI are summarized below [1]. These guidelines are based on available evidence and will likely evolve with further SCIspecific research in CMD. For some recommendations that have been developed to address CMD in the general population [33, 34], current research and/or strong clinical rationale supports modification when applied to individuals with SCI, while for others there is no current basis for a change.

\section{Assessment}

Adults with SCI should be evaluated for risk factors and components of CMD including adiposity/obesity, impaired glucose tolerance/insulin resistance, dyslipidemia, and hypertension. Assessments should be initiated on discharge from initial rehabilitation and repeated periodically thereafter. When BMI is used to determine obesity in adults with SCI, a lower cutoff of BMI $\geq 22$ kilograms per square meter $\left(\mathrm{kg} / \mathrm{m}^{2}\right)$ is suggested versus the standard $30 \mathrm{~kg} / \mathrm{m}^{2}$ used in able-bodied adults to account for loss of FFM after SCI. Techniques to measure and quantify various body components, including body fat, muscle mass, bone mineral content, and total body water provide the most accurate assessment for obesity but are presently not widely available in the clinical setting. Adults with SCI should be screened for prediabetes and diabetes based on criteria specified by American Diabetes Association [34] for fasting plasma glucose, the 2-hour plasma glucose (2-h PG) value after a 75-g oral glucose tolerance test, or A1C. Repeating the screening every three years or less is suggested if negative. Adults with SCI should be tested for dyslipidemia with a lipid panel; empirically, the guidelines recommend a frequency of at least every three years when tests are normal, and more frequently in the presence of multiple risk factors. Repeat elevated BP readings are needed to diagnose hypertension. Unique challenges in interpreting BP readings and diagnosing hypertension in individuals with SCI should be accounted for, such as the influence of posture and autonomic dysfunction.

\section{Management}

Patients and care providers should work together on optimizing lifestyle management including attention to nutrition, physical activity, and smoking cessation. A healthy diet minimizes processed meats, trans fats and sweetened beverages and emphasizes intake of vegetables, fruits, whole grains, and lean vegetable or animal protein. Participation in physical exercise should be optimized to the extent feasible within the abilities of the individuals, with a goal of $150 \mathrm{~min}$ or more of moderate-intensity activity a week. Aerobic activity should be spread throughout the week and performed in episodes of at least $10 \mathrm{~min}$. Those who are unable to comply with these guidelines should avoid being inactive and should try to engage in routine physical activities based on their ability, in consultation with their clinical team. Lifestyle interventions should be intensified in individuals with prediabetes or diabetes. In adults with Type 2 diabetes mellitus, metformin is typically the recommended first-line drug therapy [34]. Additional medications may be needed if glycemic control is not achieved despite metformin and lifestyle modifications. An endocrinologist referral should be considered and caution exercised with the use of multiple glucose-lowering medications that may increase the risk of hypoglycemia. Lack of calibration for SCI should be kept in mind when applying 
integrated cardiovascular risk equations for the management of blood cholesterol. When pharmacotherapy is indicated, statin monotherapy using at least a moderate intensity statin is typically the initial choice. Currently, there is inadequate research to back different BP goals when managing hypertension in people with SCI than what is recommended for the general population [33]. Nonpharmacological interventions, including restricting sodium intake, limiting alcohol to 1-2 drinks a day, increasing physical activity, and appropriate weight control may, by themselves, be adequate to achieve BP goal in some people with hypertension, and are important components of management for those who require antihypertensive medications for BP control. SCI-related factors should be considered when choosing antihypertensive medications, such as the need to adjust the frequency of intermittent catheterization for bladder management if a thiazide diuretic is prescribed to lower blood pressure.

\section{How should we apply guidelines in the face of significant knowledge gaps?}

\section{Acknowledge limitations and gaps in knowledge}

Recognizing knowledge gaps is critical both to guide interpretation and implementation of current guidelines and to identify areas for future research needed to enhance the validity and optimal applicability of recommended guidelines for the SCI population. Large, multicenter, prospective trials are needed to assess the cardiometabolic risk and the effectiveness and safety of interventions in people with SCI, with the results discriminated by level and completeness of injury.

\section{Apply current evidence}

While it would be optimal to base all care on high-quality evidence-based research, its absence should not be an excuse for inaction. Applying what is currently known and filling the research gaps with empirical recommendations based on clinical rationale and expert consensus is both appropriate and necessary till more definitive SCI-specific evidence becomes available. Though clinical practice guidelines are needed to improve population health, decisions at the individual patient level are best made by considering these guidelines in the context of the specific clinical, personal and environmental factors, using a patientcentered approach that emphasizes shared decision-making.

\section{Account for $\mathrm{SCl}$-related factors}

Supine hypertension may be missed if blood pressure is only taken in the sitting position in people with tetraplegia instead of measuring both seated and supine blood pressure. Adiposity may be underestimated if BMI cut-offs for able-bodied adults are used as markers for obesity. Depending on the level of injury, energy expenditure is lower in people with SCI after the post-acute phase than in able-bodied individuals, so a lower calorie consumption should be factored in nutritional counseling and planning $[27,35]$.

\section{Evolve with future research}

Current guidelines are likely to evolve with accumulation of further SCI-specific research in cardiometabolic disease. The need for additional investigation in several areas is recognized to enhance the validity and optimal applicability of recommended guidelines for the SCI population. However, for now, the current guidelines serve as a valuable resource for identification and management of cardiometabolic risk after SCI and for positively impacting the health of this patient population.

\section{Disclaimer}

Contents of this article do not represent the views of the Department of Veterans Affairs or the United States Government.

\section{Compliance with ethical standards}

Conflict of interest The author declares that he has no conflict of interest.

Publisher's note Springer Nature remains neutral with regard to jurisdictional claims in published maps and institutional affiliations.

\section{References}

1. Nash MS, Groah SL, Gater D, Dyson-Hudson TA, Lieberman JA, Myers J. et al. Identification and Management of Cardiometabolic Risk after Spinal Cord Injury: Clinical Practice Guideline for Health Care Providers. Top Spinal Cord Inj Rehabil. 2018;24:379-423.

2. Chopra AS, Miyatani M, Craven BC. Cardiovascular disease risk in individuals with chronic spinal cord injury: prevalence of untreated risk factors and poor adherence to treatment guidelines. J Spinal Cord Med. 2018;41:2-9.

3. Cragg JJ, Noonan VK, Krassioukov A, Borisoff J. Cardiovascular disease and spinal cord injury: results from a national population health survey. Neurology. 2013;81:723-8.

4. Sabharwal S. Cardiovascular and autonomic consequences: ischemic heart disease. In: Sabharwal S (ed). Essentials of spinal cord medicine. New York, NY: Demos Medical Publishing; 2014; p 271-7.

5. Phillips AA, Krassioukov AV. Contemporary cardiovascular concerns after spinal cord injury: mechanisms, maladaptations, and management. J Neurotrauma. 2015;32:1927-42. 
6. Bauman WA, Korsten MA, Radulovic M, Schilero GJ, Wecht JM, Spungen AM. 31st g. Heiner sell lectureship: secondary medical consequences of spinal cord injury. Top Spinal Cord Inj Rehabil. 2012;18:354-78.

7. Bauman WA, Spungen AM. Carbohydrate and lipid metabolism in chronic spinal cord injury. J Spinal Cord Med. 2001;24:266-77.

8. Cragg JJ, Noonan VK, Dvorak M, Krassioukov A, Mancini GB, Borisoff JF. Spinal cord injury and type 2 diabetes: results from a population health survey. Neurology. 2013;81:1864-8.

9. Nash MS, Tractenberg RE, Mendez AJ, David M, Ljungberg IH, Tinsley EA, et al. Cardiometabolic syndrome in people with spinal cord injury/disease: guideline-derived and nonguideline risk components in a pooled sample. Arch Phys Med Rehabil. 2016;97:1696-705.

10. Bauman WA, Kahn NN, Grimm DR, Spungen AM. Risk factors for atherogenesis and cardiovascular autonomic function in persons with spinal cord injury. Spinal Cord. 1999;37:601-16.

11. Warburton DE, Eng JJ, Krassioukov A, Sproule S. Cardiovascular health and exercise rehabilitation in spinal cord injury. Top Spinal Cord Inj Rehabil. 2007;13:98-122.

12. Wilt TJ, Carlson KF, Goldish GD, MacDonald R, Niewoehner C, Rutks I et al. Carbohydrate and lipid disorders and relevant considerations in persons with spinal cord injury. Evid Rep Technol Assess Full Rep. 2008;163:1-95.

13. LaVela SL, Evans CT, Prohaska TR, Miskevics S, Ganesh SP, Weaver FM. Males aging with a spinal cord injury: prevalence of cardiovascular and metabolic conditions. Arch Phys Med Rehabil. 2012;93:90-5.

14. Selassie A, Snipe L, Focht KL, Welldaregay W. Baseline prevalence of heart diseases, hypertension, diabetes, and obesity in persons with acute traumatic spinal cord injury: potential threats in the recovery trajectory. Top Spinal Cord Inj Rehabil. 2013;19:172-82.

15. Wahman K, Nash MS, Lewis JE, Seiger A, Levi R. Increased cardiovascular disease risk in Swedish persons with paraplegia: the Stockholm spinal cord injury study. J Rehabil Med. 2010;42:489-92.

16. Hitzig SL, Tonack M, Campbell KA, McGillivray CF, Boschen KA, Richards K, et al. Secondary health complications in an aging Canadian spinal cord injury sample. Am J Phys Med Rehabil. 2008;87:545-55.

17. Soden RJ, Walsh J, Middleton JW, Craven ML, Rutkowski SB, Yeo JD. Causes of death after spinal cord injury. Spinal Cord. 2000;38:604-10.

18. Garshick E, Kelley A, Cohen SA, Garrison A, Tun CG, Gagnon $\mathrm{D}$, et al. A prospective assessment of mortality in chronic spinal cord injury. Spinal Cord. 2005;43:408-16.

19. Kressler J, Cowan RE, Bigford GE, Nash MS. Reducing cardiometabolic disease in spinal cord injury. Phys Med Rehabil Clin N Am. 2014;25:573-604.viii.
20. Jensen MP, Molton IR, Groah SL, Campbell ML, Charlifue S, Chiodo A, et al. Secondary health conditions in individuals aging with SCI: terminology, concepts and analytic approaches. Spinal Cord. 2012;50:373-8.

21. Libin A, Tinsley EA, Nash MS, Mendez AJ, Burns P, Elrod M, et al. Cardiometabolic risk clustering in spinal cord injury: results of exploratory factor analysis. Top Spinal Cord Inj Rehabil. 2013;19:183-94.

22. Walker WC, Khokhar MS. Silent cardiac ischemia in cervical spinal cord injury: case study. Arch Phys Med Rehabil. 1992;73:91-4.

23. Sanford P, Sabharwal S. Diagnosis of myocardial infarction in a patient with complete tetraplegia. J Spinal Cord Med. 2000;23 (Suppl 1):47.

24. Stiens SA, Johnson MC, Lyman PJ. Cardiac rehabilitation in patients with spinal cord injuries. In: Halar EM (ed). Cardiac rehabilitation: Part II. Phys Med Rehabil Clin North Am. 1995;6:263-96.

25. Bauman WA, Raza M, Spungen AM, Machac J. Cardiac stress testing with thallium-201 imaging reveals silent ischemia in individuals with paraplegia. Arch Phys Med Rehabil. 1994;75:946-50.

26. Lee CS, Lu YH, Lee ST, Lin CC, Ding HJ. Evaluating the prevalence of silent coronary artery disease in asymptomatic patients with spinal cord injury. Int Heart J. 2006;47:325-30.

27. Gater DR Jr. Obesity after spinal cord injury. Phys Med Rehabil Clin N Am. 2007;18:333-51.vii.

28. Teasell RW, Arnold JM, Krassioukov A, Delaney GA. Cardiovascular consequences of loss of supraspinal control of the sympathetic nervous system after spinal cord injury. Arch Phys Med Rehabil. 2000;81:506-16.

29. Figoni SF. Perspectives on cardiovascular fitness and SCI. J Am Paraplegia Soc. 1990;13:63-71.

30. Figoni SF. Exercise responses and quadriplegia. Med Sci Sports Exerc. 1993;25:433-41.

31. Coutts KD, Rhodes EC, McKenzie DC. Maximal exercise responses of tetraplegics and paraplegics. J Appl Physiol Respir Environ Exerc Physiol. 1983;55:479-82.

32. Peiffer SC, Blust P, Leyson JF. Nutritional assessment of the spinal cord injured patient. J Am Diet Assoc. 1981;78:501-5.

33. Arnett DK, Blumenthal RS, Albert MA, Buroker AB, Goldberger ZD, Hahn EJ, et al. 2019 ACC/AHA guideline on the primary prevention of cardiovascular disease: a report of the American College of Cardiology/American Heart Association Task Force on Clinical Practice Guidelines. Circulation. 2019;140:e596-e646.

34. American Diabetes Association. Standards of Medical Care in Diabetes-2018. Clin Diabetes. 2018;36:14-37.

35. Buchholz AC, Pencharz PB. Energy expenditure in chronic spinal cord injury. Curr Opin Clin Nutr Metab Care. 2004;7:635-9. 